\title{
La metáfora del fuego en la cosmología poética de José Emilio Pacheco
}

\author{
Romuald-Achille Mahop Ma Mahop \\ École Normale Supérieure de Yaoundé (Camerún) \\ mahorom2006@yahoo.fr
}

\begin{abstract}
Resumen: La meditación acerca de la materia constituye uno de los pilares de la escritura poética de José Emilio Pacheco. El tratamiento reservado en esta poesía a la realidad telúrica y a las fuerzas en presencia permite hablar de una verdadera cosmología poética. El presente artículo indaga el significado y el papel de la metáfora del "fuego" en la construcción de este sistema poético, siguiendo una triple perspectiva: el fuego como paradoja de la persistencia y del cambio, el fuego como fuerza destructora endógena y el fuego como propiedad cíclica de la materia.
\end{abstract}

Aвstract: Meditation about matter is a dominant issue in José Emilio Pacheco's lyrical world. The treatment given to telluric reality and to the forces involved in this process lead to a real poetic cosmology. This essay investigates the function of the metaphor of "fire" in Pacheco's poetry, underlining its significance through three main perspectives: fire considered as a paradox of permanence and change, fire seen like a destructive endogenous power and, finally, fire considered as a cyclical pattern of reality.

Palabras Clave: José Emilio Pacheco, cosmología poética, metáfora del fuego. KeYwords: José Emilio Pacheco, poetic cosmology, metaphor of fire.

Uno de los elementos constructores del sistema poético del mexicano José Emilio Pacheco es la reflexión acerca de las leyes que gobiernan el universo físico en el que está inmerso el hombre. El presente artículo se propone abordar esta auténtica cosmología poética a partir de la metáfora del "fuego", particularmente sugerente desde el segundo volumen lírico del poeta mexicano: El reposo del fuego. En mi opinión, esta metáfora se puede abordar siguiendo tres perspectivas fundamentales que permiten apreciar la complejidad y la riqueza de la cuestión. Habría que señalar, desde un principio, que la imagen del "fuego" en la cosmología poética de José Emilio Pacheco procede de una asimilación del pensamiento presocrático en general, pero también de algunos aspectos de las cosmogonías prehispánicas como la náhuatl, por ejemplo. 
De hecho, el sentimiento de la fugacidad del mundo, la preocupación por la duración de la materia y la pregunta acerca de la naturaleza efímera del ser humano vienen precedidos en el tiempo por una vena lírica que se remonta a varios siglos atrás. Ya están claramente presentes, por ejemplo, en la poesía de Nezahualcóyotl, Rey poeta de Texcoco, en cuya obra la fugacidad de la existencia se acompaña de la mutación de la propia materia. ${ }^{1}$ Esto me permite matizar la habitual limitación de la cosmovisión pachequiana a las influencias de la filosofía presocrática, como si la herencia prehispánica a la que acabo de aludir fuese insignificante. En este sentido, resulta extraño que la crítica destaque el interés de Pacheco por las culturas del México antiguo, visible en sus traducciones, en sus aproximaciones y en la reapropiación de la tradición lírica náhuatl, pero que a la hora de analizar su cosmología poética ciertas aproximaciones enfaticen más bien la influencia presocrática (Topletz 1983; Docter 1991; Carrillo Juárez 2008). Me parece que, al tiempo que se reconoce la presencia del pensamiento de Heráclito y otros filósofos presocráticos en nuestro poeta, hay que destacar precisamente la similitud entre estos ecos presocráticos y algunos aspectos de la cosmovisión prehispánica. ${ }^{2}$ Esta última está puesta de manifiesto

1 “¿Es que acaso se vive de verdad en la tierra? / ¡No por siempre en la tierra, / sólo breve tiempo aquí! / Aunque sea jade: también se quiebra, / aunque sea oro, también se hiende, / y aun el plumaje de quetzal se desgarra: / ¡No por siempre en la tierra: / sólo breve tiempo aquí!" (63).

${ }^{2}$ Viene al caso recordar, por ejemplo, como hace Miguel León-Portilla en Los antiguos mexicanos, la sucesión de Soles procedente del pensamiento prehispánico, teoría según la cual "el mundo había existido, no una, sino varias veces consecutivas. La que se llamó 'primera fundamentación de la tierra', había tenido lugar hacía muchos milenios. Tantos, que en conjunto habían existido ya cuatro soles y cuatro tierras, anteriores a la época presente. En esas edades llamadas 'Soles' por los antiguos mexicanos, había tenido lugar una cierta evolución 'en espiral', en la que aparecieron formas cada vez mejores de seres humanos, de plantas y de alimentos. Las cuatro fuerzas primordiales —agua, tierra, fuego y viento (curiosa coincidencia con el pensamiento clásico de Occidente y del Asia) — habían presidido esas edades o Soles, hasta llegar a la quinta época, designada como la del 'Sol de movimiento'”. Hay que notar en esta cosmología precolombina que no solo los seres humanos conocen una progresiva transformación, sino también los restantes componentes de la naturaleza, como las plantas y los alimentos que sirven de sustento a los hombres. León-Portilla ańade precisamente, acerca de esta idea, que cada una de las edades o "Soles" se acompañó de una transformación en la naturaleza de los componentes; el maíz, por ejemplo, ha atravesado sucesivas mutaciones hasta llegar a tener su aspecto actual (13-14). 
en estudios como el de Carmen Alemany Bay donde se subraya la dialéctica que surge de las antinomias de la destrucción y de la armonía en la poetización del pasado precolombino y colonial mexicano. Este diálogo con el pasado nacional, según la estudiosa, "no es prioritario en su poética pero sí necesario porque esta temática ayudó al autor en sus primeros ańos de poeta a configurar la complejidad del mundo mexicano" y a potenciar la práctica de la intertextualidad que ocupa un lugar destacado a lo largo de su producción poética (5). Siguiendo una perspectiva similar a la de Alemany Bay, Elizabeth Monasterios Pérez analiza el poema "Árbol entre dos muros" de Los elementos de la noche bajo la perspectiva de la dualidad y del movimiento. Para Monasterios Pérez, "puesto que dualidad y movimiento son precisamente los componentes básicos de la lógica cultural náhuatl, no parece arbitrario postular que el poema está recreando una temporalidad cuyo origen remite a la experiencia náhuatl del tiempo, expresada en los obstinados nacimientos del sol que, seguidos de inminentes desapariciones, dan paso a la eterna fricción de los contrarios" (43). Estamos invitados, pues, a entender la metáfora del "fuego" a lo largo de este estudio como un producto de la conjugación de las dos principales cosmologías en presencia: la presocrática y la prehispánica. Analizaré la metáfora del fuego aquí bajo una triple perspectiva. En primer lugar, estudiaré el fuego como una paradoja de la persistencia y del cambio. Después, me interesaré en el fuego como una fuerza destructora endógena. Por último, mostraré en qué medida la metáfora ígnea postula una ciclicidad de la materia.

\section{El fuego como paradoja de la PeRsistencia y del CAMbio}

Penetrar la cosmología poética de José Emilio Pacheco supone enfrentarse a la paradoja entre la persistencia de la materia y su transformación. El signo global que fecunda la dinámica expresiva de la escritura en este caso es el concepto de "movimiento", tributario de las metamorfosis de la realidad física. Esto implica que toda quietud es solo aparente, efímera, y que la inmovilidad de la naturaleza es, en realidad, una lenta transformación y circulación. No se debe confundir, no obstante, el principio de "circulación" y el de ciclicidad al que volveré después. Partiendo de la imagen heracliteana del "agua", Raúl Dorra explica, 
en efecto, que "el movimiento de las aguas no dibuja la figura de un círculo pues las aguas están en permanente tránsito o, diríamos, en permanente circulación. Circulación, subrayemos, no es lo mismo que circularidad pues esta es el continuo retorno de lo mismo". En cambio, la circularidad "es el continuo transcurrir de lo que se aleja hasta ausentarse, esto es, una continua, plural metamorfosis" (62). El fuego se refiere, entonces, a una transformación no exenta de novedad, y no a la eterna repetición nietzscheana de lo idéntico. Esta diferenciación es fundamental para poner de manifiesto las relaciones entre la cosmología poética de José Emilio Pacheco y la prehispánica. Debo recordar, en este sentido, las precisiones de Miguel León-Portilla, según las cuales para los antiguos mexicanos, "cada edad o sol termina siempre con un cataclismo. Pero en vez de volver a repetirse una historia, fatalmente idéntica a la anterior, el nuevo ciclo ascendente en espiral, va originando formas mejores" (14). Se cumple, entonces, esa "eterna circulación de las transformaciones" que poetiza Pacheco en su "Escolio a Jorge Manrique”, texto al que volveré más adelante.

La tensión entre fuerzas contrarias se presenta generalmente en la poesía de Pacheco bajo la afirmación simultánea de la permanencia de los elementos y de su metamorfosis. La pugna se sitúa en el orden del tiempo en cuanto agente de las transformaciones. Jean Brun recuerda que, en Heráclito, "el devenir es lo que asegura la síntesis del ser y del no ser" (48). Del mismo modo, la dimensión efímera de los elementos cósmicos en José Emilio Pacheco no podrá situarse fuera del marco del constante enfrentamiento de los opuestos. Quiero decir que toda caducidad de la materia se insertará necesariamente en la dialéctica entre nacimiento y muerte, presencia y ausencia, esplendor y marchitamiento, pero nunca como procesos cerrados en sí mismos. Lo resume una de las composiciones emblemáticas del heraclitismo poético de Pacheco, el texto "Don de Heráclito" de El reposo del fuego:

El reposo del fuego es tomar forma con su pleno poder de transformarse.

Fuego del aire y soledad del fuego

al incendiar el aire hecho de fuego.

Fuego es el mundo que se extingue y cambia

para durar (fue siempre) eternamente. 
Las cosas hoy dispersas se reúnen

y las que están más próximas se alejan.

(T.T.2010,3 "Don de Heráclito": 44-45)

El fragmento 76 de Heráclito actúa en esta estrofa, no solo a través de la presencia explícita de algunos de los elementos primordiales que intervienen en la dialéctica cósmica —el "fuego" y el "aire" — sino también mediante la lucha de los contrarios. José Miguel Oviedo asocia en semejantes casos la poética de Pacheco con el pensamiento de Empédocles y Heráclito. Según el crítico, las ideas del primero se habrían introducido en la poesía de Pacheco a través de la obra de Bachelard (su Psicoanálisis del fuego especialmente), mientras que la cosmovisión heracliteana sería esencialmente fruto de "un punto de encuentro con la poesía borgiana, cuyos ecos se pueden rastrear en varias partes de la obra del mexicano". Así, prosigue Oviedo, "el Agua, el Fuego y el Aire se combinan en el texto a través de un juego de reiteraciones y variaciones que apuntan a los grandes temas del mismo: el cambio y la permanencia" (47). ${ }^{4}$ Acaso debería añadirse que, aunque el texto se presenta explícitamente como un diálogo con el pensador de Éfeso, la visión coincide con el fuego de la cosmología náhuatl que también defiende, como ya he dicho, las incesantes transformaciones del universo. Esa dialéctica es descrita por Betina Bahía Diwan de Masri como la "danza mortal"

\footnotetext{
${ }^{3}$ A lo largo de este artículo, esta abreviatura remite a la última recopilación publicada en 2010 de Tarde o temprano (Poemas 1958-2009) de la que provienen las citas del corpus.

${ }^{4}$ Me pregunto si José Miguel Oviedo tiene razón cuando hace transitar el legado del pensamiento presocrático en José Emilio Pacheco por Bachelard y Borges. Me parece más que probable que el poeta mexicano haya leído directamente a Empédocles y a Heráclito, sobre todo si atendemos el diálogo que algunas de sus composiciones mantienen con las ideas de esos filósofos griegos presocráticos. Poemas como el que acabo de reproducir, "Don de Heráclito", o "Siempre Heráclito" de Irás y no volverás, son algunos de los ejemplos que abogan por una inmersión directa de Pacheco en las fuentes de la filosofía griega antigua. Judith Roman Topletz incluso habla, en este sentido, de evidentes paráfrasis de varios fragmentos de Heráclito perceptibles en la poesía de Pacheco - "Pacheco's obvious paraphrases of several fragments of the Greek philosopher" (35) - , lo cual sugiere un conocimiento de primera mano de la obra de los pensadores antiguos. Esto no impide, por supuesto, que el diálogo con los filósofos mencionados se haya consolidado en Pacheco a través del redescubrimiento de sus ideas en escritores y pensadores modernos como Bachelard o Borges.
} 
de "Eros y Thánatos", un proceso en el que "vida y muerte, día y noche, luz y oscuridad" se suceden "en una inmanencia total de un presagio que señala la creación del mundo y también la de un poema" (19-20). La estudiosa incluso percibe atisbos cabalísticos en el libro, sobre todo a partir del sistema de fragmentación externa de las composiciones. ${ }^{5} \mathrm{El}$ poema "Don de Heráclito" es clave en este caso porque pone en escena la metáfora del fuego que "arde", por así decirlo, en muchas páginas de Pacheco, evidente en títulos como el de su segundo poemario. Acerca de dicho título precisamente, Luis Antonio de Villena ha destacado su índole melancólica. Según Villena, con la fórmula "El reposo del fuego", el poeta se percataría de que el mundo es presidido por la ley del "fuego" heracliteano, que propugna una concepción dinámica del universo (28). Judith Roman Topletz opina lo mismo cuando alude al "restless fire, a metaphor for a world in which reality undergoes perpetual transmutations" (34). ${ }^{6}$ Betina Bahía Diwan de Masri se hace eco de estas visiones cuando define el título del segundo poemario de Pacheco como "una metáfora que trata de ordenar el caos solo por un instante, dejando tiempo y espacio para que la voz del poeta establezca la unión de las dos fuerzas opuestas en el poema”. Para esta crítica, "fuego y reposo son dos metáforas efímeras irreconciliables" que "juntas, recobran la temporalidad regeneradora del tiempo que no cesa en destruir y metamorfosear las formas con una imagen de negación que afirma el desastre y la pesadumbre". La cohabitación del "fuego" con el "reposo" convierte al segundo en elemento "activo", debido a la influencia del elemento ígneo (13).

Thomas Hoeksema, por su parte, explica la paradoja del título del siguiente modo: "la destrucción (fuego) está moderada por la estabilidad y la armonía (reposo). La relación entre estas dos fuerzas es multidimensional y dialéctica”. Para Hoeksema, el segundo volumen poético

5 Para Diwan de Masri, El reposo del fuego es "un poema unitario, tripartito. Cada parte tiene 15 poemas cortos que forman el movimiento rítmico de las palabras versificadas libremente. Es posible que el poeta aluda a la paz del mundo, pues, según la Cábala, el día 15 de $A v$ (julio a agosto, según el calendario lunar) reina la paz y la armonía entre el hombre, el cosmos y Dios" (14). La estudiosa considera los elementos de la naturaleza que figuran en El reposo... como "símbolos cabalísticos del orden y de la armonía de la vida y del mundo" (19).

6 "el reposo del fuego, una metáfora para un mundo en el que la realidad sufre perpetuas transmutaciones" (traducción mía). 
de Pacheco se debe entender como "un intento de sintetizar dos fuerzas discordes y antagónicas y de infundir en el caos y en el cambio alguna forma y algún orden". Además, "la presencia simultánea de reposo y conflagración establece los polos de tensión en este libro y, por lo tanto, en toda su poesía subsiguiente". Según el crítico, "el reposo debe ser identificado con vida, unión y armonía", no como un estado pasivo, sino como "un reposo activo debido a su relación con el fuego. El fuego se identifica con cambio destructivo y muerte, pero tiene que ser un cambio constructivo debido a su relación con el reposo". Entender la dinámica que rige la imagen del "reposo del fuego" de Pacheco es, entonces, captar el matiz que existe entre la afirmación de "un reposo en el fuego" y "un reposo del fuego" (85-86).

Ya que me referiré con frecuencia a la visión heracliteana del fuego, merece aclarar, con todo, que según estudiosos como Brun, se ha simplificado a menudo erróneamente el "fuego" de Heráclito. En el filósofo de Éfeso, el fuego no es un simple principio físico sino que encierra varias otras posibles significaciones. Una de ellas alude al "fuego" como una fuerza superior que rige el universo: "en primer lugar el fuego es lo que, en tanto que rayo, dirige el universo". Ese principio rector se asemeja a una instancia trascendente, lo cual se justificaría por la probabilidad de que "Heráclito, como todos los hombres de su época, pensara que una especie de 'arriba en sí inscribiéndose en una verticalidad cósmica, permitía afirmar que el 'allí arriba', donde mora el dios, debe diferenciarse del 'aquí abajo' en donde viven los humanos". El fuego puede aludir también a las leyes propias del cosmos que está "en llamas porque, en primer lugar, está hecho de llamas, de fuego". Para Heráclito, "el fuego es, en efecto, el elemento primero y el principio de todas las demás sustancias. Él es quien en el transcurso de sus metamorfosis corre a través del agua, la tierra y el aire. Está presente en el ciclo de la materia, de la que reviste todas las formas". La tercera significación del fuego heracliteano, según Brun, hace referencia a la esencia del universo; el cosmos en sí mismo es fuego y "no ha sido creado por Dios $\mathrm{u}$ hombre alguno, pero siempre fue, es y será un fuego eternamente vivo". Por consiguiente, el devenir del mundo no es sino "aquello por lo que éste se consume". Una cuarta interpretación del fuego hace de este el fin último del mundo, ya que el universo "está destinado a un incendio final". Sin embargo, matiza Brun, este fin del mundo no se ha de entender en el sentido del Apocalipsis sino que debemos aprehen- 
derlo situándonos en la imagen de una circunferencia donde el fin y el comienzo coinciden (65 y ss.).

Buena parte de estas acepciones insisten en la ausencia de toda norma exógena que gobierne la vida cósmica. Todo se desarrolla en la dinámica medular del universo y la energía que mueve todas las cosas es la ley del fuego. El interés de estas aclaraciones es ayudar a esclarecer el sentido melancólico de la expresión pachequiana del "reposo del fuego" tal como la entienden Villena y Hoeksema. Así, el "reposo" sería el ansia de una quietud que no se consigue nunca, porque siempre está perturbada por la vitalidad ígnea de las olas. ${ }^{7} \mathrm{El}$ "Escolio a Jorge Manrique" de No me preguntes cómo pasa el tiempo, al que ya me he referido, le permite a José Emilio Pacheco reactivar la herencia poética hispánica para proponer nuevos horizontes de lectura a textos consagrados por la tradición literaria y el tiempo. El poema consiste en tres breves versos que dialogan enriquecedoramente con las Coplas... de Manrique, pero enfocándolas desde la perspectiva del fuego cósmico de las transformaciones:

\author{
La mar no es el morir \\ sino la eterna \\ circulación de las transformaciones.
}

(T.T.2010, "Escolio a Jorge Manrique": 82)

El título del poema define una intertextualidad que se refuerza tipográficamente por medio de las cursivas del primer verso. La diferencia gráfica entre las palabras que integran este verso resalta el signo de la negación —el adverbio "no"- expresando una contradicción que culmina en los dos versos siguientes. Raúl Dorra comenta este recurso gráfico de la siguiente manera: "dado que se ubican en la misma línea,

\footnotetext{
7 Al evocar la metáfora de las "mareas", aludo a la imagen empleada por Mary Kathryn Docter en su tesis ya citada, para describir la poesía de Pacheco. Para la estudiosa, "the tide is never still. Paradoxically, its restless, continually moving ever changing nature displays patterns of both dynamic power and undeviating constancy. The poetry of José Emilio Pacheco resembles the turning tides" (1). ["La marea no es nunca quieta. Paradójicamente, la falta de reposo característica de su cambio continuo de naturaleza pone de manifiesto a la vez aspectos de un poder dinámico y de una constancia persistente. La poesía de José Emilio Pacheco se parece a la marea cambiante”] (traducción mía).
} 
este primer verso produce el paradójico efecto de resaltar la negación -no- que es la única palabra que aquí está en letra redonda". Todo ocurre "como si se tratara de una inversión de los significantes tipográficos, el tipo que se supone normal, o neutro, es el que adquiere un efecto de amplificación: La mar no es el morir". El efecto visual del verso, prosigue Dorra, "es una representación de su propio contenido semántico o, dicho con más propiedad, otra forma de ponderar la 'circulación de las transformaciones"” (59). ${ }^{8}$ En Manrique, huelga recordarlo, la imagen de la "mar" es el segundo término de una alegoría expresada por "nuestras vidas son los ríos / que van a dar en la mar, / que es el morir". La "mar" es la desembocadura inexorable de toda existencia humana, la culminación de un proceso en el que el elemento acuático se cierra sobre la materia sin ninguna posibilidad de rescate. Esta idea se afirma perentoriamente en los versos "allí van los señoríos / derechos a se acabar e consumir". La inmersión del ser en el mar manriqueano toma, pues, la forma de una aniquilación irremisible. El "Escolio..." de Pacheco, en cambio, consiste en rebatir esta tesis, en transformar la muerte finalista del poeta medieval español en acontecimiento cósmico y fecundo. De esta manera, el texto trasciende la dimensión prioritariamente humana

${ }^{8}$ Dorra hace observar igualmente cómo la transformación de la que habla el poema de Pacheco se va produciendo en el plano creativo a través de las distintas configuraciones de la segmentación de la línea poética a lo largo de las ediciones. Así, de la versión de 1969 a la de 2000, pasando por la de 1980, "el poema circula y se transforma". La primera versión presenta una distribución de las palabras en la que se "enfatiza el movimiento"; se "trata de que la mirada que cae sobre las líneas no se detenga en ningún punto sino que descienda y se desplace a una velocidad uniforme, a pesar de una relativamente suave vacilación después de la palabra 'eterna' que parece quedar ubicada entre dos unidades sintácticas". La segunda distribución tipográfica, por su parte, "construye un movimiento que tiende a detenerse — ahora con decisión- en la palabra 'eterna' (palabra a la que le sucede un dilatado blanco) para luego retomar y acelerar el ritmo con que la mirada pasa sobre la última línea". En la última versión, finalmente, "las tres líneas que componen el poema son tres unidades cuya relación puede establecerse de dos maneras: en tanto la segunda línea comienza con una conjunción adversativa (la mar no es el morir / sino la eterna) podríamos decir que esta segunda línea debe reunirse por contraposición —adversación — con la primera pero en tanto termina con un adjetivo (eterna) cuyo correspondiente sustantivo (circulación) está en la línea que le sigue, podría decirse que lo que corresponde es reunir la segunda con la tercera. Así el adjetivo 'eterna' sirve de pivote para que la lectura, después de una vacilación en este caso relativamente prolongada, caiga sobre la tercera línea ('circulación de las transformaciones') depositando sobre ella el mayor peso semántico" (59-60). 
que poseía en Manrique para adquirir una generalidad material, cósmica. Esta viene potenciada por el plural "las transformaciones", referencia no solo a las metamorfosis de los elementos, sino también a la variedad de componentes susceptibles de renovarse en la matriz telúrica de las aguas marítimas.

Nos hallamos, por lo tanto, ante una visión del mar como teatro de transformaciones beneficiosas para el equilibrio natural. En este caso, Pacheco propone un efímero esencialmente positivo, una fugacidad cósmica cuya energía nace de la coexistencia dialéctica entre la persistencia y el cambio. El poema "La rueda", de El silencio de la luna, insiste sobre la necesidad de este vértigo inacabable, sobre las virtudes del "fuego" como motor de vida:

Sólo es eterno el fuego que nos mira vivir.

Sólo perdura la ceniza.

Funda y fecunda la transformación,

el incesante cambio que manda en todo.

Sólo el cambio no cambia y su permanencia es nuestra finitud.

Hay que aceptarla y asumirla: ser

del instante,

material dispuesto

a seguir en la rueda del hoy aquí

y mañana en ninguna parte.

(T.T.2010, “La rueda": 410-411)

Celebración de la metamorfosis, himno a las propiedades transformadoras del fuego que reconfigura en cada instante los seres y las cosas, este poema recuerda en muchos aspectos aquel "variar segundo tras segundo" que elogia el hablante lírico de "Contraelegía", en Irás y no volverás. Las dos composiciones proponen una verdadera dialéctica de lo efimero, donde lo fugaz adquiere una dimensión eterna. Y puesto que "sólo perdura la ceniza", el propio "instante", cifra por antonomasia de lo efímero, se hace eternamente presente, no a la manera de la verticali- 
dad bachelardiana del ahora, sino en la rotación continua de la "rueda". La aparente contrariedad de la afirmación "Sólo el cambio no cambia", significa que, por tener como propiedad la combustión, el fuego no precisa de reposo o, más exactamente, que ese reposo es la propia combustión. En este sentido, se puede entender que el "cambio" no cambia, precisamente porque la inestabilidad ya forma parte de su esencia. La imagen de la "rueda" sirve para ilustrar este hecho, ya que adquiere su significado, no en el reposo, sino en la continua rotación. Notemos de paso cómo ese movimiento es subrayado por la sonoridad de los significantes "funda y fecunda" en el tercer verso, sugiriendo una redundancia acústica que apunta a la energía transformadora del cambio. De hecho la escansión correcta de este segmento de verso prohíbe no advertir la magia reiterativa de las sílabas que le confieren su sentido rítmico.

El segundo aspecto de la metáfora del fuego en la cosmología poética de Pacheco surge de la capacidad destructora de la materia. Esta vez, la transformación se produce a través de cataclismos naturales que, más allá de su violencia devastadora, revelan una energía interna incontrolable.

\section{EL FUEGO COMO FUERZA DESTRUCTORA ENDÓGENA}

Según Elizabeth Monasterios Pérez, la poesía de Pacheco, al igual que la de Octavio Paz, por ejemplo, se nutre de cosmología prehispánica. Con todo, prosigue Monasterios Pérez, Pacheco se demarca de Paz mediante la configuración de un "principio apocalíptico". La estudiosa constata que "Paz viste el pensamiento náhuatl de reminiscencias orientalistas en las que prima el principio de reconciliación de contrarios", hecho que ha llevado a buena parte de los estudiosos de la poesía paciana a recurrir a las teorías de Mircea Eliade sobre el eterno retorno, algo poco apropiado a la visión náhuatl del mundo. Monasterios Pérez no ve este imperativo de circularidad en la cosmogonía náhuatl, "donde, al contrario, toda creación contiene el principio de su destrucción y donde ha desaparecido el simbolismo del centro". Para ella, "la poética pachequiana, profundamente vinculada a un discurso de desolación sobre la tierra, comporta este principio de irreconciliabilidad" (44). Me gustaría insistir sobre todo en este sentimiento destructivo que se desprende de ciertas composiciones de Pacheco, pero como consecuencia de una catástrofe endógena, es decir, como fruto del fuego inherente al cosmos. 
Si el mundo es regido por el dinamismo del fuego, este actúa en el seno mismo de la tierra y es capaz de desencadenar las más graves catástrofes naturales. El octavo poemario de José Emilio Pacheco, Miro la tierra (1986), ilustra esta fragilidad de la materia. La primera sección del libro, "Las ruinas de México (Elegía del retorno)", insiste especialmente en la inmanencia de esta capacidad desintegradora, como se puede comprobar en los siguientes fragmentos:

\section{1}

Absurda es la materia que se desploma, la penetrada de vacío, la hueca.

No: la materia no se destruye, la forma que le damos se pulveriza, nuestras obras se hacen añicos.

2

La tierra gira sostenida en el fuego.

Duerme en un polvorín.

Trae en su interior una hoguera, un infierno sólido que de repente se convierte en abismo.

3

La piedra de lo profundo late en su sima.

$\mathrm{Al}$ despetrificarse rompe su pacto con la inmovilidad y se transforma en el ariete de la muerte.

\section{4}

De adentro viene el golpe, la cabalgata sombría, la estampida de lo invisible, explosión de lo que suponemos inmóvil y bulle siempre.

Se alza el infierno para hundir la tierra. El Vesubio estalla por dentro. 
La bomba asciende en vez de caer.

Brota el rayo en un pozo de tinieblas.

(T.T.2010, “Las ruinas de México...”: 307-308)

El poema comienza con una declaración que después se corrige: “Absurda es la materia que se desploma”. El hablante se desdice enseguida, proclamando la invulnerabilidad de la realidad: "No: la materia no se destruye". Al abjurar de sus declaraciones iniciales, el poeta sintetiza la contradicción aparente entre la solidez de la materia y su fragilidad. Como observa Michael J. Doudoroff, esta primera sección se abre con "una consideración sobre la materia y la inestabilidad de la forma y describe el terremoto primero en términos geológicos que conducen a una categoría de absolutos generales" (163). Asumida como una entidad inestable, la tierra parece "penetrada de vacío" o simplemente "hueca". El hablante lírico entiende, sin embargo, que el derrumbamiento de los elementos no destruye la materia sino las creaciones humanas. Las obras erigidas por la técnica tratan de moldear a la naturaleza, pero un leve temblor de esta las "pulveriza" y "nuestras obras se hacen añicos".

El segundo fragmento retoma la ley del "fuego" del segundo poemario, insistiendo esta vez en la sospecha de una conspiración ígnea encubierta bajo el reposo aparente de las formas. La quietud de la tierra se vuelve sospechosa, ya que "duerme en un polvorín", referencia a una paz equívoca y traidora. En los cuatro últimos fragmentos, se insiste sobre el carácter endógeno de la destrucción que madura desde dentro para luego estallar por fuera bajo la forma de violentos cataclismos. El resto del poema expresa el poderío de la naturaleza que convierte incluso las construcciones humanas en trampas feroces. Se impone nuevamente la visión del cosmos como caos - caosmos - y toda certeza sobre la solidez de la materia se volatiliza y deja lugar a una sucesión de interrogaciones:

Cosmos es caos pero no lo sabíamos

o no alcanzamos a entenderlo.

¿El planeta al girar desciende

en abismos de fuego helado?

¿Gira la tierra o cae? ¿Es la caída

infinita el destino de la materia?

(T.T.2010, “Las ruinas de México...": 311) 
Impera un sentimiento trágico, sin duda por la inmediatez del desastre causado por el terremoto de México de 1985 que inspiró estos poemas. ${ }^{9}$ El título del libro, Miro la tierra, enuncia desoladamente la actitud de un sujeto que contempla alrededor suyo un universo de ruinas y de escombros. La naturaleza obliga al yo lírico a observar su poder y a valorar las implicaciones nefastas de la ley heracliteana del fuego que había formulado desde su segundo poemario. Selena Millares declara que "las fuerzas terrígenas han de rebelarse contra sus agresores" y Miro la tierra es una "doble elegía, por las víctimas y por ese mundo que agoniza” (1882). Michael J. Doudoroff, por su parte, considera la primera sección del libro como "una respuesta directa e inmediata al terremoto de 1985 en la ciudad de México", lo que explica la ausencia del "distanciamiento y la ironía de visiones más críticas o contemplativas". Doudoroff añade que la profecía de la catástrofe, rastreable en la poesía anterior de Pacheco, alcanza en este libro "su realización y su 'aftershock', o sismo secundario" (163). Un texto que también ilustra esta precariedad intrínseca de la materia es "Lumbre en el aire" de $L a$ arena errante:

Estallan los jardines de la pólvora

en el cielo oscurísimo y su aplomo.

Estruendo frente al mar que se encarniza

desde la eternidad contra las rocas.

A cada instante otro Big bang.

Nacen astros, cometas, aerolitos.

Todo es ala y fugacidad

en la galaxia de esta lumbre.

Mundos de luz que viven un instante.

Luego se funden y se vuelven nada.

9 El poema "Las ruinas de México (Elegía del retorno)" se acompaña de una nota explicativa, según la cual la composición está dirigida a la memoria de los que murieron durante el terremoto y a los que prestaron un apoyo moral al poeta durante aquellos difíciles momentos (véase nota: 307). 
Como esta noche en que hemos visto arder cuerpos fugaces sobre el mar eterno.

(T.T.2010, "Lumbre en el aire": 573)

El poema describe un universo en continua ruina que da la sensación en ocasiones de revivir la imaginería nerudiana de Residencia en la tierra. Flota en el texto un sentimiento de ocaso, potenciado por el léxico de la hecatombe y del tumulto, cuyas figuras más evidentes son "estallan", "pólvora”, "estruendo", “Big bang" y "se funden”. Hay una impresión inquietante que se consigue mediante signos que sugieren el desencadenamiento apocalíptico de las fuerzas cósmicas. Así, "estallan los jardines de la pólvora" y el cielo se hace "oscurísimo" como para crear un ambiente diluvial. El lector se enfrenta con un mundo de turbulencia donde los elementos se descontrolan como si tuviera lugar "otro Big bang", o como si el universo se desmoronara para autoregenerarse en "astros", "cometas" y "aerolitos" que "nacen" "a cada instante". Los elementos solo sobreviven en un breve intervalo y "luego se funden y se vuelven nada". Rocío Oviedo indica que esta sensación de desmoronamiento es común a los poetas de la generación de Pacheco. Forma parte de "un sentido del Apocalipsis que ocupa prácticamente todo el siglo $\mathrm{xx}$, y que surgía ya en las últimas manifestaciones del Modernismo" (63). La persistente destrucción sería, pues, un legado de la Vanguardia, de los motivos del vacío y de la angustia tributarios del pensamiento filosófico de las primeras décadas del siglo xx (50). Oviedo añade que lo que fecunda esta estética es la creencia en "la victoria o la venganza de la naturaleza frente a la técnica" (63). Con esta actitud, Pacheco compartiría "la versión clásica de Heráclito en lugar de la de Bergson (preferido por las Vanguardias). En ambos filósofos el tiempo conlleva el proceso de destrucción que afecta a la materia" (71).

La sensación de desmoronamiento y de vértigo nace en "Lumbre en el aire" de la confusión de lo terrestre con lo estelar o sideral. Mientras los signos "jardines", "mar" o "rocas" remiten a realidades telúricas, "cielo", "astros", "cometas", "aerolitos" "galaxia" sitúan al lector en la dimensión cósmica superior. Todo ello culmina con la postulación de un "Big bang". Lo particular en este "Big bang" es que adviene "a cada instante" y no remite a la teoría más difundida sobre el nacimiento del universo. Significa que en la cosmología poética de José Emilio Pacheco, el principio del fuego actúa en ocasiones como una experien- 
cia inmediata o cotidiana en la que podemos asistir al espectáculo de la materia modificándose ante nuestra mirada. Es lo que ocurre, por ejemplo, con las transformaciones de las "dunas" en el poema epónimo "La arena errante":

Los misteriosos médanos cambiaban de forma con el viento.

Me parecían las nubes que al derrumbarse por tierra se transformaban en arena errante.

De mañana jugaba en esas dunas sin forma.

$\mathrm{Al}$ regresar por la tarde

ya eran diferentes y no me hablaban.

Cuando soplaba el Norte hacían estragos en casa.

Lluvia de arena como el mar del tiempo.

Lluvia de tiempo como el mar de arena.

Cristal de sal la tierra entera inasible.

Viento que se filtraba entre los dedos.

Horas en fuga, vida sin retorno.

Médanos nómadas.

(T.T.2010, “La arena errante": 502-503)

El hablante rememora un espectáculo de la vida natural. La reminiscencia infantil sirve de base para una reflexión sobre la mutabilidad. El cambio constante de apariencia de las "dunas" expresa la preeminencia del movimiento sobre la quietud, del fuego sobre el reposo. Los dos impulsos no se refieren solo a una experiencia material, sino que también inscriben estas mutaciones en un orden temporal. En otras palabras, el poema pone en acción la "arena errante" del desierto y la de la sucesión cronológica, ambas reunidas o sintácticamente trabadas en la estructura paralelística "Lluvia de arena como el mar del tiempo / Lluvia de tiempo como el mar de arena". La metamorfosis de las dunas a lo largo de la jornada no describe solamente un fenómeno ecológico; es otra manifestación del fuego cósmico, de la perpetua movilidad de los elementos.

El verso "Médanos nómadas" que cierra el fragmento subraya esta falta de reposo que reina en las dunas desérticas, asimiladas a un pueblo en eterna trashumancia. El verso interesa también desde el punto de 
vista de su juego silábico paronomásico. En efecto, la asociación de los significantes "médanos" y "nómadas" en un mismo sintagma nominal - "médanos nómadas" - produce una eufonía que se explica por el hecho de que uno es casi la imagen sonora inversa del otro. Esta equivalencia fonética, es decir, la permutabilidad aproximativa de los dos significantes, refuerza la idea expresada en el plano semántico. De hecho, lo que define los "médanos" es precisamente su nomadismo, su movimiento incesante bajo las fuerzas conjugadas del viento y del tiempo. Quisiera finalmente analizar el tercer aspecto de la metáfora del fuego en la cosmología poética de Pacheco: el retorno cíclico de la materia.

\section{El FUEGo COMO CICLICIDAD DE LA MATERIA}

La obra del mexicano suele mostrar la naturaleza y sus componentes en un continuo renacimiento cíclico, aunque también existe alguna excepción a esta regla. ${ }^{10}$ En el pensamiento de Heráclito, la ciclicidad del mundo nace de la constante lucha de los opuestos. En esta dialéctica implacable, cada fuerza vive de la muerte de la que la precede y también alimenta a la que la sigue. Así, afirma el filósofo de Éfeso, "vive el fuego la muerte de la tierra y vive el aire la muerte del fuego; el agua vive la muerte del aire; la tierra, la del agua" (79).

Algunos estudiosos de Pacheco han asimilado la dialéctica de los elementos con una circularidad que subraya la coincidencia entre el fin y el comienzo, pensando no solo en el eterno retorno característico de Heráclito, sino también en la cosmología azteca. Pura López Colomé, por ejemplo, analiza el tema del tiempo en José Emilio Pacheco bajo la imagen del Ouroboros. Este símbolo se refiere, por un lado, a "las

${ }^{10}$ Una excepción es quizá la de los últimos versos del poema epónimo "Los elementos de la noche": "Nada se restituye ni devuelve / el verdor a la tierra calcinada. / Ni el agua en su destierro sucederá a la fuente / ni los huesos del águila volverán por las alas" (T.T.2010, "Los elementos de la noche": 19). Como reconoce Judith Roman Topletz, "the utter desolation of this poem is an exception to the rule in Pacheco's poetry; both in the early stages and in later poems, the heraclitean influence of the cyclical nature of time predominates over the vision of a total holocaust" (20). ["La total desolación de este poema es una excepción a la regla en la poesía de Pacheco; tanto en las primeras etapas como en poemas posteriores, la influencia heracliteana de la naturaleza cíclica del tiempo predomina sobre la visión de un completo holocausto"] (traducción mía). 
duplicidades tan evidentes en el autor, a la vez oscuro y claro, oscilante entre los principios ético y estético, entre la culpa y la absolución" y, por otro, a "la continuidad de la vida por medio de un animal". El Ouroboros representa, en efecto, "una serpiente que se muerde la cola". Este acto de autofagia y autogénesis "encarna la idea primitiva de la naturaleza autosuficiente, nietzscheana también, que retorna a sí misma, a su principio, en un patrón cíclico" (71). La idea supone que tanto el universo como los componentes que lo construyen, se renuevan, mueren y nacen, se apagan y vuelven a encenderse. Desde una perspectiva similar, Selena Millares asegura que la filiación solar de la llama en este caso remite a "creencias ancestrales mexicanas, sobre un Dios que da la vida y se alimenta de la muerte". Del mismo modo, lo ígneo es creador de ciclicidad cuando pensamos en la "destrucción renovadora" del Apocalipsis bíblico (1881). Desde Los elementos de la noche, ya se manifiestan los estigmas textuales de una renovación cósmica. Podría evocarse, por ejemplo, la primera composición del libro, el poema "Árbol entre dos muros" que, en el orden cósmico, sugiere la rotación diurna y nocturna:

Sitiado entre dos noches

el día alza su espada de claridad,

hace vibrar al esplendor del mundo,

brilla en el paso del reloj al minuto.

Mientras avanza el día se devora.

Y cuando llega ante la puerta roja

arde su luz, su don, su llama

y derriba a los ojos de sus reinos hipnóticos.

Ante el día calcinado dejo caer tu nombre:

haz de letras hurañas,

isla en llamas que brota y se destruye.

Es medianoche a la mitad del siglo.

Todo es el huracán y el viento en fuga.

Todo nos interroga y recrimina.

Pero nada responde,

nada persiste contra el fluir del día. 
Atrás el tiempo lucha contra el cielo.

Agua y musgo devoran las señales, navegación inmóvil de la savia, muro de nuestras sombras enlazadas, hoguera que se abisma en sus rescoldos.

(T.T.2010, “Árbol entre dos muros":15)

La antinomia de los signos "día" y "noche", que comienza desde las metáforas del título, sugiere una rotación que se opera en el orden cósmico. El momento diurno tiene que ceder necesariamente el paso a la noche, en una sucesión sin la cual cada uno de los elementos tomado aisladamente perdería su valor. El fluir del día solo adquiere sentido en relación con la inminencia de la noche. Valeria Añón analiza las representaciones de lo nocturno en la poesía de Pacheco desde la perspectiva del retorno prehispánico del dios. Así, la noche y la sangre corresponden al "espacio del sacrificio y del incierto retorno del dios" y remiten a "la esperanza de ver salir el sol entre los dos volcanes para que el ciclo recomience" (3-4). En el ejemplo de arriba, aunque el sujeto lírico vive la rotación "día/noche" como un motivo de preocupación existencial y de evocación melancólica, también es consciente de que el proceso se inscribe en una imperiosa dinámica cósmica. La misma dialéctica de la sucesión diurna y nocturna es perceptible en "Mar que amanece":

En el alba navega el gran mar solo.

Alza su sed de nube vuelta espuma

y en la arena

duerme como las barcas.

De repente amanece,

gloria que se propaga, cotidiano

nacimiento del mundo.

El otro mar nocturno

bajo la sal ha muerto.

(T.T.2010, "Mar que amanece": 17)

A primera vista, lo que motiva el impulso lírico del poema es la impresión surgida de la contemplación de una alborada naciente. No obs- 
tante, en el fondo de esta emoción matutina anida la sensación de que ha ocurrido una renovación entera de la materia. Esta percepción se observa sobre todo a partir de la segunda estrofa, mediante el "cotidiano / nacimiento del mundo". Todo ocurre como si "el otro mar nocturno" hubiera cedido lugar a uno distinto, totalmente transformado en la transfiguración nocturna. La belleza que se intuye en este instante matinal es el resultado de una renovación del paisaje. Un determinado aspecto del mundo se ha apagado para dar paso al rejuvenecimiento de la naturaleza, y el signo "muerto", del último verso, encarna esta mutación. Si en "Mar que amanece" el alba representa la renovación del paisaje, en varias otras composiciones de Pacheco los elementos vegetales suelen servir de modelo para la regeneración cíclica de la materia. Esta visión se aprecia en textos como "La granada", de Los trabajos del mar, o "Insistencia" de Islas a la deriva. En "Insistencia", por ejemplo, la contemplación de la nieve es una oportunidad para afirmar los ciclos del agua:

Una vez más hablemos de la nieve. Digamos: su virtud cardinal es el silencio.

Sabe nacer con impecable suavidad en la noche y al despertar la vemos adueñada de la tierra y los árboles.

¿Adónde irá la nieve que hoy te rodea?

La nieve que interminablemente circunda

la casa y la ciudad volverá al aire, será agua, nube y luego otra vez nieve.

Tú no tienes sus virtudes mutantes y te irás, morirás, serás tierra.

Serás polvo en que baje a apagarse la nieve.

(T.T.2010, “Insistencia”: 182)

La primera estrofa poetiza el advenimiento nocturno y silencioso de la nieve sin otro fin que el de dar cuenta de una emoción ante un fenómeno natural. El título del poema, "Insistencia", se debe interpretar teniendo en cuenta que el tema de la nieve domina a lo largo de la sección entera en la que el texto aparece, "Escenas del invierno en Canadá", lo cual explica también el primer verso del poema: "Una vez más hablemos de la nieve". "Insistencia" es, entonces, una asunción 
discursiva y conversacional de la redundancia del tema a lo largo de la sección. La segunda estrofa, en cambio, remite directamente a las sucesivas transformaciones que permiten el restablecimiento de la nieve. Así, la nieve que ahora "circunda / la casa y la ciudad volverá al aire, / será agua, nube y luego otra vez nieve".

El itinerario cíclico de la nieve está descrito como un privilegio prohibido a los seres humanos: "Tú no tienes sus virtudes mutantes". La irrupción de la segunda persona verbal permite que el enunciador dirija la palabra a un interlocutor ficticio que es a la vez el propio yo textual y el lector. Como apunta Mary Kathryn Docter, uno de los recursos del ocultamiento de la voz autorial en la poesía de Pacheco consiste en ceder el sitio a una segunda persona del singular, como consecuencia de un desdoblamiento del yo: "the use of second person singular highlights the poet's split person, his separation from self" (299). Francisca Noguerol opina lo mismo cuando incluye el "tú" entre las "más conocidas estrategias de enmascaramiento" de Pacheco, una segunda persona verbal que puede remitir tanto a un "desdoblamiento del 'yo" " como a un interlocutor del subjetivo "yo" (83), en esa peculiar ficción comunicativa que cada poema instaura. Hay que añadir, sin embargo, que este enmascaramiento del yo bajo el tú apunta también al resto de los hombres, ya que ninguna existencia puede usurpar los ciclos de la nieve. En el segundo fragmento de "El silencio de la luna: tema y variaciones", de El silencio de la luna, este poder de resurrección se expresa a través de un elemento vegetal, las "siemprevivas":

Noviembre, y no me fijo en los troncos desnudos, sólo en las siemprevivas y en las plantas perennes. Ignoro la respuesta: su verdor, enmedio del desierto de la grisura, ¿es permanencia, obcecación, desafío?

O quizá por indiferentes desconocen la noche de los muertos. $\mathrm{Al}$ prescindir del viaje renunciaron al goce de la resurrección que habrán de disfrutar sus semejantes: siemprevivas porque antes ya se han muerto, perennes porque saben renacer como nadie.

(T.T.2010, “El silencio...”, fragmento 2: 467-468) 
El poema arranca de una contemplación del paisaje en pleno mes de noviembre. El "verdor" de las siemprevivas contrasta con un panorama vegetal dominado por la "grisura" de la deshojadura otoñal. La mirada del yo poético se fija preferentemente "en las siemprevivas y en las plantas perennes". Esta percepción selectiva denota un interés por el tema de la supervivencia de las especies que se formula como un enigma irresuelto: "Ignoro la respuesta". La interrogación consiste en esclarecer si las sempervirentes hojas de las "siemprevivas" son una manifestación de su "permanencia", de una obstinación por parte de la planta o de su "desafío" a las leyes cósmicas. La reflexión se hace en dos etapas: la primera consiste en interpretar la sempervirencia de esas plantas como una invulnerabilidad ante la muerte: "desconocen la noche de los muertos". En este caso, la inmortalidad absoluta no es una ventaja porque "al prescindir del viaje renunciaron al goce / de la resurrección / que habrán de disfrutar sus semejantes". La segunda etapa del razonamiento resuelve la duda a partir de una interpretación basada en el sentido del nombre mismo de la planta: "siemprevivas porque antes ya se han muerto, / perennes porque saben renacer como nadie". El poeta no concibe, entonces, una supervivencia que no subsuma la dialéctica "muerte/resurrección". Yvette Jiménez de Báez comenta, acerca de este poema, que "morir para renacer implica la aceptación del viaje; la lucha azarosa y la muerte como paso a la eternidad; como un saber renacer único. De no ser así, prevalecería la indiferencia, la no vida”. Para la estudiosa, la aspiración a la renovación se transparenta ya en el signo "noviembre": "en noviembre — penúltimo mes del año, tiempo de manifestación del poema, se crea la ruptura de la linealidad y se posibilita la entrada de otro tiempo" (298-299). Otros ejemplos de Pacheco donde se expresan ideas similares acerca del renacimiento de los elementos vegetales son "Fragancia", "Hoja", "Invierno" o "La estación total" de La arena errante. Examinemos el primero mencionado:

\author{
Si la flor \\ que enciende las tinieblas con su perfume \\ no piensa, no tiene voluntad, no sabe nada, \\ ¿por qué entonces se obstina \\ en soltar el aroma que llega a mí \\ y me obliga a decir estas palabras? \\ Quizá menospreciamos el silencio:
}


en efecto, me ve, me compadece, me otorga el don secreto de su olor un instante.

Porque si uno se acaba y pulveriza, en cambio ella en sus resurrecciones será flor siempre para aromar nuestra noche.

(T.T.2010, "Fragancia": 530)

Los dos últimos versos del poema enfatizan la perpetuidad de la flor, contrastándola una vez más con el género humano que "se acaba y pulveriza". La prosopopeya, apreciable en la compasión de la flor hacia los seres humanos, sirve de instrumento para realzar el privilegio vegetal de la refloración estacional respecto a la vida irrepetible de los humanos. La obstinación de la flor en cumplir con su destino de flor, es decir, en "soltar el aroma que llega a mí", pierde su aparente absurdidad y deviene en lección de conducta para los hombres: "Quizá menospreciamos el silencio: / en efecto, me ve, me compadece, / me otorga el don secreto de su olor un instante".

El poema "Hoja" nos mantiene en este elogio de la materia cíclica, solo que ahora la "flor" ya no goza del privilegio de la resurrección sino que se convierte en paradigma de una caducidad irrepetible:

Para que recomience

lo que se terminó

alzo un pétalo

del cerezo inocente e indestructible

y lo arrojo al viento.

El árbol regresará en la estación justa.

Para la flor no existe segundo acto.

Para ella de verdad no hay vuelta de hoja.

(T.T.2010, “Нoja”: 531)

Resulta curioso que, después de haber sido alabada por su renovación constante, la flor ya no goce de la perdurabilidad en esta composición. Ahora la floración estacional es protagonizada por el "cerezo inocente e indestructible" que "regresará en la estación justa". En cambio, "para la 
flor no existe segundo acto". Creo que la distinción se debe a que, ahora, la flor está tomada singularmente. Ya no se trata de las distintas flores susceptibles de nacer de una misma planta, sino de una de ellas, aislada de sus restantes resurrecciones. En "Hoja", el elemento que retiene la mirada del sujeto es el "árbol" que "regresará en la estación justa" y no una de sus partes. La "vuelta de hoja" de la que habla el último verso se refiere a la planta en su conjunto y no a sus flores. Dicho de otro modo, las hojas que volverán no serán nunca exactamente las mismas que las que murieron antes. Podemos decir, por lo tanto, que si la renovación cíclica de los elementos cósmicos consagra el retorno de las especies, no se trata nunca, rigurosamente hablando, de una identidad perfecta. Recordemos, para aclarar mejor este punto, el fragmento de Heráclito según el cual "el Sol es nuevo cada día" (36). El sol es a la vez idéntico y distinto del que amaneció el día anterior, acaso porque la ley de la revolución impide que haya en el universo coincidencias exactas.

La ciclicidad es especialmente visible en la sucesión de las estaciones. José Emilio Pacheco se muestra atento a esa variación natural de las temporadas que se aprecia en el poema epónimo "No me preguntes cómo pasa el tiempo". Una vez más, la intuición de la repetibilidad estacional no prescinde de la irreversibilidad de la experiencia humana:
Al lugar que fue nuestro llega el invierno
y cruzan por el aire las bandadas que emigran.
Después renacerá la primavera,
revivirán las flores que sembraste.
Pero en cambio nosotros
ya nunca más veremos
la casa entre la niebla.

(T.T.2010, "No me preguntes cómo pasa el tiempo": 79)

La irrupción del invierno en el "lugar que fue nuestro" es un motivo de lamentación melancólica porque estorba la dicha del yo lírico. La llegada de la nueva temporada se expresa con una referencia explícita al comienzo del invierno en el primer verso y una evocación de "las bandadas que emigran". El detalle no solo refuerza el tono melancólico del texto —al agudizar la sensación de abandono— sino que, además, sugiere visualmente uno de los fenómenos naturales sintomáticos del cambio de temporada: las aves se van en busca de otros climas y paisajes 
y volverán al final de la estación fría, acompasando así el ritmo de sus migraciones con las mutaciones del paisaje exterior. El texto sugiere, en este sentido, el futuro advenimiento de una primavera que reanimará las flores marchitas sembradas por la amada, ese tú al que se dirige el yo del poema. El rejuvenecimiento de la naturaleza está contrastado con la fugacidad irrecuperable del amor y de la vida humana mediante los signos adversativos "pero en cambio", así como el adverbio "nunca más".

Porque la continuidad de la materia exige su propia destrucción, la poesía de Pacheco es "una apuesta a la vida", ya que "muerte y vida no son dos polos que se rechazan sino dos contrarios que se complementan" (Olivera-Williams: 136). Ante esta persistencia de los ciclos naturales a la cual no tiene acceso el ser humano, podríamos lógicamente revertir el "Irás y no volverás" del cuarto poemario de Pacheco y decir más bien de la materia cósmica: "irás y volverás". En el poema "Pan", de Como la lluvia, la naturaleza se impone como fuerza indiferenciada, que triunfa siempre de las vidas efímeras de los individuos que la componen, incluido el ser humano. Este se alimenta de los frutos de la tierra - el "pan" como producto de la harina de trigo- y a su muerte, le devuelve a la tierra su propia sustancia para nutrir nuevos ciclos de transformaciones:

Eres lo que no miente,

Eres la verdad

Hecha de agua, de sol y tierra.

En ti podemos comer

La materia devoradora.

Al final

Seremos alimento para tu espiga.

(T.T.2010, "Pan": 639-640)

La "espiga" de trigo que aparece al final del poema demuestra que el "pan” en este caso está considerado como parte de un complejo proceso orgánico que no se inicia en la panadería, sino en el seno mismo de la tierra. El trigo proporciona la harina necesaria a la fabricación del pan. Este, a su vez, alimenta a los hombres y acaba diluyéndose en su cuerpo. $\mathrm{Al}$ fallecer, el cuerpo que ha sido sustentado durante toda la vida por este pan retorna a la tierra y fecunda el crecimiento de otras espigas 
de trigo. La materia es, por lo tanto, a la vez devorada y devoradora, engullida y engullidora, haciendo así imposible un verdadero "reposo del fuego". Contémplese desde la constante mutación de los elementos, desde la capacidad autodesintegradora de la realidad o desde los interminables ciclos de las cosas, la cosmología poética de José Emilio Pacheco nos invita sin duda a revisar nuestra actitud ante la materia en la que estamos inmersos, ante nuestras propias creaciones y a reconciliarnos con el fuego de nuestra propia mutabilidad.

\section{BibLIOGRAFÍA}

\section{Corpus}

Pacheco, José Emilio. Tarde o temprano (Poemas 1958-2009), Barcelona: Tusquets Editores, 2010.

\section{Otra bibliografía}

Alemany Bay, Carmen. "José Emilio Pacheco descubre una de sus máscaras para hablar del mundo precolombino y colonial" [2005]. Artículo en línea disponible en $<$ http://rua.ua.es/dspace/bitstream/10045/5938/1/ ASN_05-06_02.pdf> [consultado el 14 de marzo de 2009].

AÑón, VAlERIA. "Antigüedades mexicanas: memoria e intertextualidad en la poesía de José Emilio Pacheco", en Orbis Tertius, año XIII, núm. 14 (2008), en línea disponible en <http://www.orbistertius.unlp.edu.ar/ numeros/numero-14/04.\%20Anon.pdf> [consultado el 30 de abril de 2011].

Brun, Jean. Heráclito o el filósofo del eterno retorno. Traducción de Ana M. Aznar Menéndez. Madrid: Edaf, 1976.

Carrillo Juárez, Carmen Dolores. Espacio de confuencia. Intertextualidad y apropiación en la poesía de José Emilio Pacheco. México: El Colegio de México, 2008.

Diwan de Masri, Betina Bahía. Ensoñación cósmica. Poética de "El reposo del fuego" de José Emilio Pacheco. México: Praxis, 2004.

Docter, Mary Kathryn. The Turning Tides: The Poetry of José Emilio Pacheco. Tesis doctoral, director: José Miguel Oviedo. Los Ángeles: Universidad de California, 1991 (University Microfilms International). 
Dorra, Raúl. "Pacheco se pregunta cómo pasa el tiempo", en Pol Popovic Karic, Fidel Chávez Pérez et al. José Emilio Pacheco: perspectivas críticas, México: Siglo XXI Editores, 2006: 53-70.

Doudoroff, Michael J. "José Emilio Pacheco: recuento de la poesía, 196386", en Hugo J. Verani et al. La hoguera y el viento. José Emilio Pacheco ante la crítica, México: Era, 1994: 145-169.

HerÁclito. Heráclito: fragmentos e interpretaciones. Edición de José Luis Gallero y Carlos Eugenio López. Madrid: Árdora, 2009.

Hoensema, Thomas. "Señal desde la hoguera: la poesía de José Emilio Pacheco”, en Hugo J. Verani et al. La hoguera y el viento. José Emilio Pacheco ante la crítica, México: Era, 1994: 81-101.

JimÉnez de BÁEZ, YveTte. "La palabra poética en umbral: El silencio de la luna de José Emilio Pacheco", en Actas XII (AIH) (1995), en línea disponible en <http://cvc.cervantes.es/literatura/aih/pdf/12/aih_12_6_043. pdf $>$ [consultado el 16 de septiembre de 2010].

León-Portilla, Miguel. Los antiguos mexicanos, México: Fondo de Cultura Económica, 1983.

López Colomé, Pura. “José Emilio Pacheco en cabeza ajena”, en Letras Libres (2008), en <http://www.letraslibres.com/index.php?art=12903> [consultado el 15 de marzo de 2009].

Millares, Selena. "José Emilio Pacheco: poesía y disidencia”, en La literatura iberoamericana en el 2000. Balances, perspectivas y prospectivas. Actas del XXXIII Congreso del Instituto Internacional de Literatura Iberoamericana. Edición de Carmen Ruiz Barrionuevo et al. Salamanca: Universidad de Salamanca, 2003: 1879-1886.

Monasterios Pérez, Elizabeth. Dilemas de la poesía latinoamericana de fin de siglo. José Emilio Pacheco y Jaime Saenz. La Paz: Plural Editores, 2001.

Nezahuacóyotl. Nezahualcóyotl. Edición de José Luis Martínez. México: Secretaría de Educación Pública, 1972.

Noguerol, Francisca. "Introducción”, en José Emilio Pacheco, Contraelegía. Antología. Edición de Francisca Noguerol. Salamanca: Ediciones Universidad de Salamanca / Patrimonio Nacional, 2009: 9-99.

Olivera-Williams, María Rosa. "La muerte como fuerza creadora en la poesía de José Emilio Pacheco”, en Hugo J. Verani et al. La hoguera y el viento. José Emilio Pacheco ante la crítica. México: Era, 1994: 134-144.

Oviedo, José Miguel. "José Emilio Pacheco: la poesía como Ready-Made”, en Hugo J. Verani et al. La hoguera y el viento. José Emilio Pacheco ante la crítica. México: Era, 1994: 43-61.

Oviedo, Rocío. "Continuidad de la vanguardia en México: José Emilio Pacheco", en Luis Sainz de Medrano et al. Las vanguardias tardias en la poesía hispanoamericana. Roma: Bulzoni Editore, 1993: 45-71. 
Topletz, Judith Roman. Time in the Poetry of José Emilio Pacheco: Images, Themes, Poetics. Tesis doctoral, director: Merlin Forster. Austin: Universidad de Texas at Austin, 1983 (University Microfilms International).

Villena, Luis Antonio De. "Introducción”, en José Emilio Pacheco. Antología. Madrid: Júcar, 1986.

FECHA DE RECEPCIÓN: 29 de octubre de 2012

FECHA DE ACEPTACIÓN: 28 de enero de 2013 